\section{Resources available for informed prenatal decisions}

To the Editor: We read with interest the article by Polomaki et al., "DNA Sequencing of Maternal Plasma to Detect Down Syndrome: An International Clinical Validation Study," concerning Sequenom's new, highly sensitive screening test for Down syndrome. ${ }^{1}$ We agree wholeheartedly with the authors' recognition that "educational materials for both patients and providers need to be developed and validated to help ensure informed decision making." Fortunately, resources already exist that should be shared with expectant mothers to ensure informed decision making.

In 2010, Lettercase published "Understanding a Down Syndrome Diagnosis." Through a Joseph P. Kennedy Foundation grant, a collaborative effort led by the National Down Syndrome Congress and the National Down Syndrome Society recognized this booklet as the "gold standard" of information to provide to patients receiving a prenatal diagnosis. The booklet then went through a round of intensive review from the American College of Obstetricians and Gynecologists (ACOG), the American College of Medical Genetics, and the National Society of Genetic Counselors (NSGC). The booklet's back cover notes that it was prepared with the assistance of representatives from ACOG, NSGC, the American College of Medical Genetics, the National Down Syndrome Congress, and the National Down Syndrome Society. This booklet is available for dissemination from Canister (http://shop.canisterstudio.com).

Complementing this written resource is the free, online training module, funded by the Centers for Disease Control and Prevention, for health-care providers on how to deliver a diagnosis in a sensitive manner: http://www.brighter-tomorrows. org. Kleinert et al. report that the program "yielded significant improvement in knowledge and level of comfort" in "imparting accurate, balanced information about Down syndrome pre- and postnatally."2

In addition to these resources, Downsyndromepregnancy.org is an online site for those expectant mothers who have decided to continue their pregnancies after a prenatal diagnosis. The website provides a free, downloadable book that addresses the unique concerns of these patients. In addition, the National Down Syndrome Adoption Network (NDSAN) (http://www. ndsan.org) is a national registry of over 250 families wanting to adopt a child with Down syndrome.

Each of these resources- "Understanding a Down Syndrome Diagnosis," brighter-tomorrows.org, Downsyndromepregnancy.org, and the National Down Syndrome Adoption Network-is recognized by the NSGC's guidelines for practitioners to provide to patients when delivering a diagnosis. ${ }^{3}$
The NSGC and ACOG practice guidelines, as well as the Prenatally and Postnatally Diagnosed Conditions Awareness Act, further recognize the value of referring patients to national and local support organizations. ${ }^{3,4,5}$ New studies of parents, siblings, and individuals with Down syndrome by Skotko, Levine, and Goldstein are also available to inform physicians and patients about the Down syndrome experience. ${ }^{6,7,8}$

As Palomaki et al. ${ }^{1}$ recognize, educational materials are needed to ensure that informed decisions are made following a prenatal testing result. This year, the NSGC and the American College of Medical Genetics provided a copy of "Understanding a Down Syndrome Diagnosis" to each of its members, and thousands more copies were distributed to practicing obstetricians. These educational materials and supporting resources are currently available, and practice guidelines and federal law recognize the need for them to be provided to expectant mothers. It is our hope that testing companies and health-care providers will invest in providing these resources to their patients in order for their patients' autonomy to be truly respected.

\section{DISCLOSURE}

The authors do not have any commercial association that might pose or create a conflict of interest with the information presented in the submitted Commentary. Mark Leach serves in a non-paid capacity on the Board of Directors for Down Syndrome Affiliates in Action and Down Syndrome of Louisville. He has a daughter with Down syndrome. Brian Skotko serves in a non-paid capacity on the Board of Directors of the National Down Syndrome Society, the Massachusetts Down Syndrome Congress, and Band of Angels Foundation. He further serves in a non-paid capacity on the Professional Advisory Council of the National Down Syndrome Congress. Brian Skotko has a sister with Down syndrome.

\section{Mark W. Leach ${ }^{1}$ and Brian G. Skotko ${ }^{2}$}

${ }^{1}$ Informed Decision Making Task Force, Down Syndrome Affiliates in Action, Louisville, Kentucky, USA; ${ }^{2}$ Down Syndrome Program, Children's Hospital Boston, Boston,

Massachusetts, USA.E-mail: mleach@stites.com

\section{REFERENCES}

1. Palomaki GE, Kloza MS, Lambert-Messerlian GM, et al. DNA sequencing of maternal plasma to detect Down syndrome: an international clinical validation study. Genet Med 2012:14, this issue.

2. Kleinert HL, Lunney CA, Campbell L, Ferguson JE 2nd. Improving residents' understanding of issues, comfort levels, and patient needs regarding screening for and diagnosing Down syndrome. Am J Obstet Gynecol 2009;201:328.e1-328.e6.

3. Sheets $K B$, Crissman BG, Feist $C D$, et al. Practice guidelines for communicating a prenatal or postnatal diagnosis of down syndrome: recommendations of the national society of genetic counselors. J Genet Couns 2011;20:432-441

4. ACOG Committee on Practice Bulletins. ACOG practice bulletin no 88: invasive prenatal testing for aneuploidy. Obstet Gynecol 2007;110: 1459-1467. 
5. Public Law: Prenatally and Postnatally Diagnosed Conditions Awareness Act of 2008, Pub. L. No. 110-374 (8 October 2008).

6. Skotko BG, Levine SP, Goldstein R. Having a son or daughter with Down syndrome: perspectives from mothers and fathers. Am J Med Genet Part A 2011;155:23335-23347.

7. Skotko BG, Levine SP, Goldstein R. Having a brother or sister with Down syndrome: perspectives from siblings. Am J Med Genet A 2011; 155A:2348-2359.

8. Skotko BG, Levine SP, Goldstein R. Self-perceptions from people with Down syndrome. Am J Med Genet A 2011; 155A:2360-2369.

doi:10.1038/gim.2011.58

\section{Medical genetics and genomics curricula focused on the laboratory specialties}

To the Editor: Medical genetics is a rapidly growing medical specialty that offers unique opportunities for $\mathrm{PhD}$-degreed scientists to become board certified and participate in clinical activities, most notably by directing diagnostic laboratories. However, in our experience, few $\mathrm{PhD}$ students are aware of medical genetics as a career path and most lack an understanding of the environments in which medical geneticists work and the training requirements that lead to eligibility for certification by the American Board of Medical Genetics in a laboratory specialty. To raise awareness about medical genetics as a career path among graduate students and postdoctoral fellows at Baylor College of Medicine, two curricula focused on the laboratory specialties of medical genetics have been developed for the Graduate School of Biomedical Sciences. These curricula complement the Genetics Track Curriculum for medical students that was described by Dhar et al. in their article "Enhancing Exposure to Genetics and Genomics Through an Innovative Medical School Curriculum."

A medical genetics internship was developed to introduce medical genetics as a career path and define the work environments and training requirements associated with medical genetics. The internship consists of some components of the Genetics Track Curriculum, including an online human subjects research training course, case-based genetics conferences, journal clubs, and mentorship meetings. Internship participants also attend a "Careers in Medical Genetics" informational seminar and participate in laboratory rotations that include 1 week each in the Biochemical Genetics, Cytogenetics, and Molecular Genetics divisions of the Baylor College of Medicine Medical Genetics Laboratories. The internship requirements must be completed in 12 months. Assessment is attendance based and those completing the program receive a certificate of completion.
The internship debuted in September 2011. Interest far exceeded any capacity of the Baylor laboratories to accommodate students on rotations. As a result, a course titled "Introduction to Medical Genetics" was developed to replace the internship after the 2011-2012 academic year. The course includes 11 lectures that will define the specialty of medical genetics and its place in the practice of medicine in the United States; outline educational and training requirements for eligibility for certification by the American Board of Medical Genetics in a laboratory specialty; introduce technologies used in medical genetics laboratories; explore topics such as pharmacogenetics and cancer diagnostics; describe the regulatory environments in which clinical laboratories operate; discuss billing and reimbursement, quality control/assurance, and other operational considerations unique to clinical laboratories; delineate how clinical and analytic sensitivity/specificity and clinical utility of genetic tests are assessed; consider how copy-number and sequence variations are evaluated for clinical significance; and introduce ethical and legal issues relevant to medical genetics. Students will also complete an online human subjects training course and participate in two small group discussions focused on cases from biochemical genetics, clinical genetics/genetic counseling, cytogenetics, and molecular genetics.

In our experience, medical geneticists have only to reach out to students and postdoctoral fellows to identify individuals interested in medical genetics as a career path. It is our hope that the Genetics Track Curriculum, medical genetics internship, and/or "Introduction to Medical Genetics" course may be replicated at other institutions. Currently, we are considering how to disseminate the course materials for use by others.

\section{ACKNOWLEDGMENTS}

The authors are grateful to Shweta U. Dhar, Christine Eng, Nancy Moreno, Lorraine Potocki, and Frank Probst for their contributions to the internship and/or course.

\section{DISCLOSURE}

The authors declare no conflict of interest.

\section{Ping Fang, $P h D^{1}$ and Raye L. Alford, $P h D^{2}$}

${ }^{1}$ Department of Molecular and Human Genetics, Baylor College of Medicine, Houston, Texas, USA; ${ }^{2}$ Bobby R. Alford Department of Otolaryngology-Head and Neck Surgery, Baylor College of Medicine, Houston, Texas, USA. E-mail: ralford@bcm.edu

\section{REFERENCE}

1. Dhar SU, Alford RL, Nelson EA, Potocki L. Enhancing exposure to genetics and genomics through an innovative medical school curriculum. Genet Med 2012;14:163-167. 